\title{
Low-intensity shock wave therapy for the treatment of vasculogenic erectile dysfunction: a narrative review of technical considerations and treatment outcomes
}

\author{
Pedro Simoes de Oliveira ${ }^{1,2}$, Matthew J. Ziegelmann ${ }^{3}$ \\ ${ }^{1}$ Department of Urology, Centro Hospitalar Universitário Lisboa Norte, Hospital de Santa Maria, Lisbon, Portugal; ${ }^{2}$ Centro Cardiovascular da \\ Universidade de Lisboa, Faculdade de Medicina, Universidade de Lisboa, Lisbon, Portugal; ${ }^{3}$ Department of Urology, Mayo Clinic, Rochester, MN, USA \\ Contributions: (I) Conception and design: All authors; (II) Administrative support: All authors; (III) Provision of study materials or patients: All \\ authors; (IV) Collection and assembly of data: All authors; (V) Data analysis and interpretation: All authors; (VI) Manuscript writing: All authors; (VII) \\ Final approval of manuscript: All authors. \\ Correspondence to: Pedro Simoes de Oliveira, MD. Av. Prof. Egas Moniz MB, 1649-028, Lisbon, Portugal. Email: pedrosimoesdeoliveira@gmail.com. \\ Matthew J Ziegelmann, MD.200 First Street SW, Rochester, MN 55905, USA. Email: ziegelmann.matthew@mayo.edu.
}

\begin{abstract}
Erectile dysfunction (ED) impacts a significant portion of the aging male population. Standard treatments such as oral medications, intracavernosal injections, intraurethral suppositories, vacuum erection aids, and penile prosthesis placement have stood the test of time. Recently, there has been a growing interest in the concept of regenerative medicine with the goal of restoring or renewing functional tissue. Low intensity shock wave therapy (LiSWT) is one example of a regenerative therapy. A strong body of basic science data suggests that shockwaves, when applied to local tissue, will encourage blood vessel and nerve regeneration. Clinical evidence supports the use of LiSWT to treat conditions ranging from ischemic heart disease, musculoskeletal injuries, and even chronic non-healing wounds. LiSWT is also being used to treat male sexual dysfunction conditions such as Peyronie's Disease and ED. The first studied application of LiSWT for ED was published in 2010. Since then multiple randomized, sham-controlled trials have sought to evaluate outcomes for this novel therapy in men with vasculogenic ED. Additionally, several meta-analyses are available with pooled data suggesting that LiSWT results in a significantly greater improvement in erectile function relative to sham-control. Despite these promising findings, the current body of literature is marred by significant heterogeneity relating to treatment protocols, patient populations, and follow-up duration. Further work is necessary to determine optimal device technologies, patient characteristics, and treatment duration prior to considering LiSWT as standard of care for men with ED.
\end{abstract}

Keywords: Stem cells; platelet rich plasma; regenerative; shockwave

Submitted Sep 22, 2020. Accepted for publication Dec 31, 2020.

doi: $10.21037 /$ tau-20-1286

View this article at: http://dx.doi.org/10.21037/tau-20-1286

\section{Introduction}

Erectile dysfunction (ED) refers to the inability to achieve and/or sustain an erection satisfactory for sexual intercourse. An estimated $30-50 \%$ of men between the ages of 40-70 years of age suffer from moderate or severe ED based on data from the United States and Europe $(1,2)$. Treatment begins with lifestyle modification followed by medical therapy with phosphodiesterase-5 inhibitors (PDE5i). In medication refractory patients, or in those with intolerable side effects, published guidelines encourage clinicians to discuss established treatment such as vacuum erection devices, self-administered intracavernosal injection of erectogenic agents, intraurethral suppositories, and penile prosthesis placement (3).

Over the past several years, there has been considerable interest in the concept of "regenerative" therapies for ED 
treatment. This is logical, as ED results in anatomic and functional changes to the erectile tissue characterized by progressive cavernosal fibrosis (4). Regenerative treatments include injections of stem cells, platelet rich plasma, and low-intensity shockwave therapy (LiSWT). There is amassing animal data suggesting that these approaches may result in angiogenesis and neurogenesis, thereby "restoring" dysfunctional erectile tissue (5). To date there is limited human data to support regenerative therapies as a reliable treatment for ED. Also, the patient characteristics associated with treatment success are unclear. This has not stopped a barrage of clinics throughout the world from offering regenerative therapies for ED, sometimes with unsubstantiated claims of benefit, aggressive marketing campaigns, and exorbitant out of pocket fees (6).

Shock wave therapy (SWT) has been widely used for many years to treat many conditions. It was first described 40 years ago for the treatment of renal stones (7) and later for bone non-unions (8), chronic wounds (9), ischemic heart disease (10) and more recently for sexual dysfunction including Peyronie's Disease and erectile dysfunction (ED) $(11,12)$. High-energy SWT $(10-20 \mathrm{kV})$ is used to fragmentize urinary tract stones whereas SWT using lower energy settings $\left(<0.2 \mathrm{~mJ} / \mathrm{mm}^{2}\right)$ has been proposed to treat other conditions based on animal model data showing potential regenerative properties through angiogenesis and neurogenesis $(7,8)$.

Due to the minimally-invasive nature of this approach, SWT is an attractive treatment modality for many patients and clinicians. Of the ED regenerative therapies, LiSWT has the largest body of literature, including several randomized-controlled trials and meta-analyses (9). The results are somewhat varied, and there inherent challenges in deciphering treatment outcomes due to variations in treatment protocols (energy settings, number of shocks delivered, duration of therapy, etc.) and patient populations. Also, not all shockwave technologies are created equal and many of the devices used in commonplace are unlikely to exert any effect on erectile tissue (10). Given the controversy and lack of clarity surrounding LiSWT, as well as the increasing number of clinicians who are offering LiSWT within and outside various research protocols, herein we sought to provide a comprehensive review of LiSWT for the treatment of vasculogenic ED with emphasis on mechanism of action, device technology, published data, and future considerations (11). We present the following article in accordance with the Narrative Review Checklist (available at http://dx.doi. org/10.21037/tau-20-1286).

\section{Mechanism of action}

A shockwave refers to an acoustic disturbance with the ability to (I) carry energy, and (II) propagate through a medium $(10,12)$. The waveform itself is characterized by a high peak pressure which is achieved rapidly, and a subsequent pressure decay. The wave causes local tissue compression followed by expansion related to the tensile force of the involved tissue (13). This creates tissue stress which is hypothesized to induce neovascularization and neuronal regeneration, in part through recruitment and activation of local progenitor cells $(14,15)$.

In normal physiological conditions, vascular endothelial cells (EC) are frequently exposed to fluid shear stress created by turbulent blood flow. The forces induce cellular changes through a process known as "mechanotransduction", which is defined as a (bio)chemical response to mechanical stimuli (16). Mechanotransduction modulates EC physiology via intracellular and extracellular signaling pathways, mainly mediated by vascular endothelial growth factor (VEGF), nitric oxide synthase (NOS), and platelet derived growth factor (PDGF) leading to angiogenic gene expression in ECs $(17,18)$.

Through effects on local tissue, SWT is hypothesized to mimic fluid shear stress, stimulating VEGF and other local factor expression to enhance local angiogenesis, particularly at low energy settings (19). Hatanaka et al. demonstrated in vitro that SWT increased levels of VEGF and endothelial nitric oxide synthase (eNOS), and that caveolin-1 and $B_{1}$-integrin, constitutive proteins of caveolae, which are invaginated organelles found in the plasma membrane and responsible for cell migration, are integral for SWTinduced angiogenesis (20). Also, Sokolakis et al. found that LiSWT was associated with increased VEGF expression in the erectile tissue of naturally aged rats, as well as Liu et al., in streptozotocin-induced diabetic rats $(21,22)$. Assaly et al., in a study involving rats with hypertension-induced ED, showed that LiSWT enhanced angiogenesis in cavernosal tissue as shown by CD31 immunohistochemical expression, but there was no significant upregulation of NOS (23). The authors suggested that, although nitric oxide (NO) presence is known to be fundamental for physiological penile erection (and the pathway by which PDE5is act), the effect of LiSWT may be in part NO-independent and therefore beneficial for patients with vasculogenic ED and insufficient PDE5i response. 
Table 1 Contemporary lithotripsy technology used in erectile dysfunction

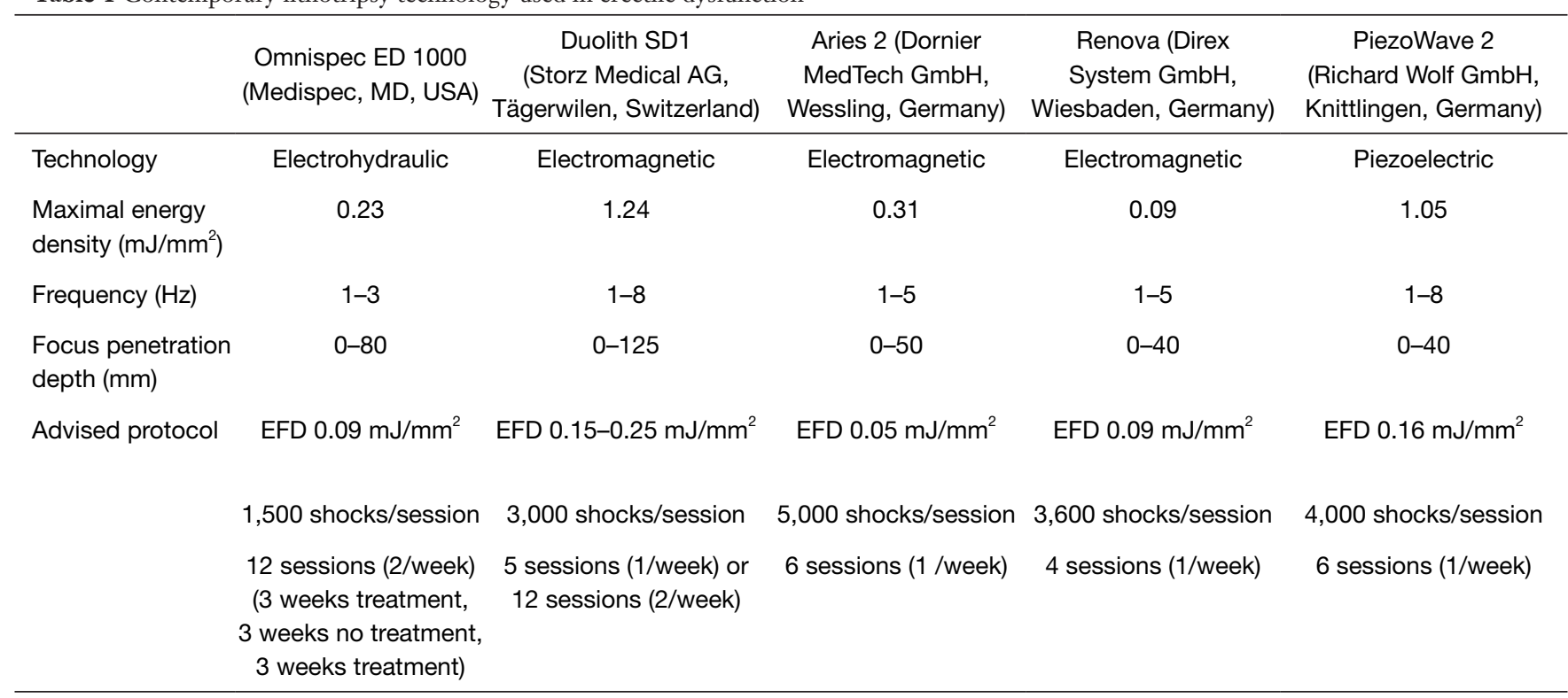

Mechanical perturbations may also induce neuronal regeneration ("neurogenesis") through local mechanisms (24). In a rat model of pelvic neurovascular injuries, Li et al. demonstrated, both in vitro and in vivo, that LiSWT improved erectile function not only by increasing the generation of new blood vessels but also by penile nerve regeneration through increased number and proliferation of Schwann cells, which are critical for nerve growth and regeneration (25). Lin et al. demonstrated that LiSWT also has the ability to activate local penile progenitor cells in a rat model, suggesting another mechanism for tissue regeneration through vascular and neuronal regeneration (26).

In conclusion, the mechanisms underlying LiSWT in the context of erectile tissue regeneration are not fully understood but likely involve angiogenesis and neurogenesis, namely mediated by growth factor expression and nerve regeneration. Local activation and recruitment of progenitor cells may also play a role. Thus, from a theoretical perspective, this approach, as compared with our standard historical treatment approaches, has the potential to restore erectile function.

\section{Technical specifications}

Shock waves are high-pressure acoustic waves characterized by a single rapid and focused pulse followed by a low-tensile phase $(10,12)$. These waves are generated by machines called lithotripters. There are three types of lithotripters in common use: electrohydraulic, electromagnetic and piezoelectric $(12,27,28)$. Electrohydraulic waves are generated by applying high voltage to electrodes to generate a spark. This produces a high-amplitude spherical wave which is then focused by a reflector. Electromagnetic waves are formed by pulling apart a metal membrane away from an electromagnetic coil using a high voltage electric pulse. The rapid forward movement of the membrane creates a planar acoustic pulse, and the shockwave is focused by an acoustic lens or reflector. Piezoelectric technology uses piezoelectric crystals that expand rapidly and synchronously when a high-voltage electric pulse is applied to them, creating a pressure wave. These crystals are distributed in a spherical way to focus the energy and do not require a lens or a reflector. Contemporary lithotripter machines differ from each other regarding specific settings, namely energy flux density (EFD), penetration depth, and frequency (Table 1). Also, each manufacturer has its own recommended protocol, including number and frequency of sessions and number of shocks per session $(10,12)$. Differences amongst machine technologies/protocols and the absence of head-to-head studies make it challenging to determine the superiority of one machine and/or protocol over another.

An important consideration that is often overlooked by patients and practitioners alike is the concept of linear versus radial wave application. This is a distinction that merits further clarification. Radial pressure waves are often described as "standard" shockwaves, but in essence they act 
similar to sound waves with a lower peak pressure and rapid outward propagation $(10,12,29)$. This results in a much shallower depth of penetration. In contrast, linear (focused) shockwave devices waves have a distinct focal point and a greater depth of penetration. Radial wave generating devices are classified as "class 1 medical devices" by the United States Food and Drug Administration (FDA) (29). This means that "professionals" are not required to have additional training prior to offering the therapy to patients and there is limited regulatory oversight. In contrast, linearwave devices are considered as "class 2 medical devices" and require FDA approval to ensure safety and treatment efficacy in the United States. Currently, the majority of providers in the United States who are offering SWT outside of a rigorous research protocol, and especially those without urologic and sexual dysfunction expertise, are using radial-wave technology (i.e., class 1 medical device), whereas the true clinical benefit may lie in the application of linear-wave technologies (i.e., class 2 medical device) (30). Unfortunately, several of the published study protocols that have evaluated LiSWT do not specify the type of ultrasound applicator probe which has significant implications on the conclusions that can be drawn with respect to one technology over another (10).

\section{Review of published clinical data}

\section{Randomized, sham-controlled clinical trials}

Vardi et al. first described LiSWT to treat ED in a 2010 pilot study involving 20 men with PDE5i-responsive erectile dysfunction (31). After a one-month period off all oral pharmacotherapy for ED (i.e. washout), participants underwent six sessions of penile LiSWT over a nine-week period. Follow-up at four-weeks revealed a significant increase in International Index of Erectile function-Erectile Function Domain (IIEF-EF) scores, from a mean 13.5 (out of maximum 30 points), to a mean $20.9, \mathrm{P}<0.001$ ). These benefits were maintained at three and six-month followup, with an average increase of 7.1 points $(\mathrm{P}=0.001)$ (31). Improvements in penile hemodynamics were also seen. The authors subsequently carried out the first randomized, double-blinded, sham-controlled trial with 67 men suffering from vasculogenic, PDE5i-responsive ED who were randomized to LiSWT versus a sham (placebo) procedure using a similar protocol to the original pilot study (32). At one-month follow-up, the mean IIEF-EF in the treatment group increased by +6.7 points, compared with +3.0 points for the sham-therapy arm $(\mathrm{P}=0.032)$. Moreover, $65 \%$ of men in the treatment arm achieved a $\geq 5$-point improvement, compared with $20 \%$ in the sham arm $(\mathrm{P}=0.0001)$. Once again, penile hemodynamics were significantly improved in the treatment arm.

Since that time, multiple retrospective, single-arm prospective, and randomized-controlled trials have been published. This includes 11 randomized, sham-controlled trials evaluating the impact of LiSWT on men with vasculogenic ED (Table 2) (32-42). Results are somewhat mixed owing in part to differences in patient populations, study design, outcomes assessed, follow-up duration, and the type of shockwave technology utilized. Treatment protocols differ in the number of shockwaves delivered with each treatment, location of the applied shockwaves, energy settings, and the number of treatments administered. Also, as discussed above, the type of shockwave transducer (i.e., linear versus radial) may impact the likelihood that a treatment effect is actually delivered at the level of the target tissue. Many of the available LiSWT included in the published literature have capabilities for both wave-types depending on the transducer (10). Unfortunately, in some instances the specific trandsucer used was not delineated, thereby adding additional uncertainty with the ability to draw definitive conclusions.

In total, $7 / 11(64 \%)$ sham-controlled trials showed a statistically significant increase in IIEF scores in the treatment arm when compared with the control arm. IIEF scores (either IIEF-EF or IIEF5 ) in the treatment arm ranged from $+1-12.5$ points, depending on the specific study (32,35,36,38-42). $3 / 11$ trials $(27 \%)$ did not show a benefit favoring LiSWT over sham $(33,34,37)$. For example, in their study of 58 patients using a similar shockwave protocol to the original trial by Vardi et al., Yee and colleagues did not identify any significant difference in outcomes, although they did identify a small benefit in subgroup analysis of men with "severe ED" (37). Trials from Fojecki et al. and Olsen et al. similarly failed to show a significant difference in outcomes for LiSWT compared with sham-control $(33,34)$. Motil and colleagues did not include a statistical analysis, but their results appear to favor LiSWT over sham, with $>80 \%$ of patients in the treatment arm achieving a minimal clinically important difference (MCID) in IIEF scores (38). This refers to a change in IIEF scores based on the severity of underlying ED prior to treatment, as defined by Rosen $e t$ al. (43).

The majority of randomized trials to date have assessed 
Table 2 Randomized, sham-controlled trials evaluating outcomes with low-intensity shockwave lithotripsy for vasculogenic erectile dysfunction

\begin{tabular}{|c|c|c|c|c|c|c|c|c|c|c|c|c|}
\hline \multirow[b]{2}{*}{ Study Info } & \multirow[b]{2}{*}{ Trial design } & \multirow{2}{*}{$\begin{array}{l}\text { \# Treated } \\
\text { [control] }\end{array}$} & \multirow{2}{*}{$\begin{array}{c}\text { Patient } \\
\text { characteristics }\end{array}$} & \multirow[b]{2}{*}{ Device } & \multicolumn{5}{|c|}{ Treatment protocol } & \multirow[b]{2}{*}{ Follow-up duration } & \multicolumn{2}{|l|}{ Treatment outcomes } \\
\hline & & & & & \# shocks/treatment ${ }^{\mathrm{F}}$ & $\begin{array}{l}\text { Frequency of } \\
\text { shocks }\end{array}$ & Energy flux density & $\begin{array}{l}\text { Treatment } \\
\text { duration }\end{array}$ & \# of treatments & & Objective questionnaire results & $P$ value \\
\hline \multirow{2}{*}{$\begin{array}{l}\text { Vardi } \\
\text { et al. (2012) }\end{array}$} & \multirow{2}{*}{$\begin{array}{l}\text { Randomized, double-blind, } \\
\text { sham-controlled }\end{array}$} & \multirow[t]{2}{*}{40 [20] } & PDE5i responders & \multirow[t]{2}{*}{ Omnispec ED1000 } & \multirow[t]{2}{*}{1,500} & \multirow[t]{2}{*}{$120 / \mathrm{min}$} & \multirow[t]{2}{*}{$0.09 \mathrm{~mJ} / \mathrm{mm}^{2}$} & \multirow[t]{2}{*}{$15 \mathrm{mins}$} & \multirow[t]{2}{*}{12} & \multirow[t]{2}{*}{1 month post } & - TX: $+6.7(+/-0.9)$ in IIEF & \multirow[t]{2}{*}{0.0322} \\
\hline & & & Vascular ED & & & & & & & & -Sham: $3.0(+/-1.4)$ in IIEF & \\
\hline \multirow{2}{*}{$\begin{array}{l}\text { Olsen } \\
\text { et al. (2015) }\end{array}$} & \multirow{2}{*}{$\begin{array}{l}\text { Randomized, double-blind, } \\
\text { sham-controlled }\end{array}$} & \multirow[t]{2}{*}{51 [54] } & PDE5i responders & \multirow[t]{2}{*}{ Storz Duolith SD1 } & \multirow[t]{2}{*}{3,000} & \multirow[t]{2}{*}{ NA } & \multirow[t]{2}{*}{$0.15 \mathrm{~mJ} / \mathrm{mm}^{2}$} & \multirow[t]{2}{*}{ NA } & \multirow[t]{2}{*}{5} & \multirow[t]{2}{*}{6 wks post } & - Tx: $34 \% \mathrm{w} />5$-pt increase in IIEF-EF & \multirow[t]{2}{*}{0.67} \\
\hline & & & Vascular ED & & & & & & & & -Sham: $22 \% \mathrm{w} />5$-pt increase in IIEF-EF & \\
\hline Yee & Randomized, double-blind, & 28 [30] & Vascular ED & Omnispec ED 1000 & 1,500 & $120 / \mathrm{min}$ & $0.09 \mathrm{~mJ} / \mathrm{mm}^{2}$ & 20 mins & 12 & 1 month post & $-\mathrm{TX}:+5.3(+/-5.5)$ in IIEF vs. Sham: $+3.8(+/-3.6)$ in IIEF & 0.24 \\
\hline & & & & & & & & & & & $\begin{array}{l}\text {-Post-hoc analysis suggested significant benefit over sham in } \\
\text { subgroup of men with "severe ED" }\end{array}$ & \\
\hline $\begin{array}{l}\text { Srini } \\
\text { et al. (2015) }\end{array}$ & $\begin{array}{l}\text { Randomized, controlled, } \\
\text { double-blind, Sham-controlled }\end{array}$ & $60[17]$ & PDE5i responders & & 1,500 & $120 / \mathrm{min}$ & $0.09 \mathrm{~mJ} / \mathrm{mm}^{2}$ & $15 \mathrm{mins}$ & 12 & $\begin{array}{l}\text { 1-month post for } \\
\text { comparison between } \\
\text { sham and tx groups }\end{array}$ & 1-month: -TX: +12.5 (+/-2.2) in IIEF; -Sham: +1.4 (+/-1.9) in IIEF & $<0.0001$ \\
\hline & & & Vascular ED & & & & & & & $\begin{array}{l}\text { 12-month post for } \\
\text { treatment arm }\end{array}$ & 12-month: -Tx: +8.7 (+/- 2.0) in IIEF & \\
\hline Kitrey & Randomized, double-blind, & $37[18]$ & Vascular ED & Omnispec ED10000 & 1,500 & $120 / \min$ & $0.09 \mathrm{~mJ} / \mathrm{mm}^{2}$ & 15 mins & 12 & 1 month post & -TX: +5 (median; IQR 0-0.95) in IIEF; MCID (40.5\%, n=15) & 0.0006 \\
\hline et al. (2016) & sham-controlled & & $\begin{array}{l}\text { PDE5i } \\
\text { non-responders }\end{array}$ & & & & & & & & -Sham: +0 (median; IQR -1-1.25) in IIEF; MCID 0\% $(n=0)$ & \\
\hline $\begin{array}{l}\text { Fojecki } \\
\text { et al. (2017) }\end{array}$ & $\begin{array}{l}\text { Randomized, double-blind, } \\
\text { sham-controlled }\end{array}$ & $58[60]$ & Vascular ED & Wolf PiezoWave/FBL10 & 1,500 & N/A & $0.09 \mathrm{~mJ} / \mathrm{mm}^{2}$ & $15 \mathrm{mins}$ & 12 & 12 months post & $\begin{array}{l}\text {-No significant difference in IIEF after active tx vs. sham ( } 38 \% \text { tx } \\
\text { "success" rate in each group) }\end{array}$ & 0.92 \\
\hline & Cross-over study & & $\begin{array}{l}\text { PDE5i } \\
\text { responders }\end{array}$ & & & & & & & & $\begin{array}{l}\text {-Low tx satisfaction ( } 50 \% \text { in sham group and } 51 \% \text { in tx group } \\
\text { based on EDITS) }\end{array}$ & \\
\hline Motil & Randomized, single-blind, & 75 [50] & Vascular ED & Wolf PiezoWave/FBL10 & 4,000 & 480 & $0.16 \mathrm{~mJ} / \mathrm{mm}^{2}$ & $33 \mathrm{mins}$ & 4 & 1-month post & $-T x: 81.3 \%$ pts (61/75) achieved MCID in IIEF-5 & NA \\
\hline et al.(2016) & sham-controlled & & $\begin{array}{l}\text { PDE5i } \\
\text { responders }\end{array}$ & & & & & & & & -Sham: $10 \%$ pts (5/10) showed improvement in IIEF-5 & \\
\hline Kalyvianakis & Randomized, double-blinded, & 30 [16] & Vascular ED & Omnispec ED1000 & 1,500 & 160 & $0.09 \mathrm{~mJ} / \mathrm{mm}^{2}$ & 20 & 12 & 3 months post & -TX:56.7\% pts achieved MCID in IIEF-EF at 3-mo & 0.003 \\
\hline et al. (2U1t) & & & $\begin{array}{l}\text { PDE5i } \\
\text { responders }\end{array}$ & & & & & & & & -Sham: $12.5 \%$ pts achieved MCID in IIEF-EF at $3 \mathrm{mo}$ & \\
\hline $\begin{array}{l}\text { Yamacake } \\
\text { et al. (2019) }\end{array}$ & $\begin{array}{l}\text { Randomized, double-blind, } \\
\text { sham-controlled }\end{array}$ & $10[10]$ & Vascular ED & Swiss DolorClast & 2,000 & 200 & $0.09 \mathrm{~mJ} / \mathrm{mm}^{2}$ & $10 \mathrm{mins}$ & 6 & 3 months post & $-T_{x}:+6.3$ in IIEF-5 vs. Sham: +1.6 in IIEF-5 & 0.018 \\
\hline & Cross-over study & & $\begin{array}{l}\text { Previous renal } \\
\text { transplant }\end{array}$ & & & & & & & & -IIEF- $5 \uparrow$ by $>5$-pts in $70 \%$ of tx group and $10 \%$ of Sham group & \\
\hline $\begin{array}{l}\text { Vinay } \\
\text { et al. (2020) }\end{array}$ & $\begin{array}{l}\text { Randomized, double-blind, } \\
\text { sham-controlled }\end{array}$ & $40[36]$ & Vascular ED & $\begin{array}{l}\text { Direx Renova } \\
\text { electromagnetic device }\end{array}$ & 5,000 & N/A & $0.09 \mathrm{~mJ} / \mathrm{mm}^{2}$ & N/A & 4 & $\begin{array}{l}1,3 \text {, and } \\
6 \text { months post }\end{array}$ & $\begin{array}{l}\text { 1-month: -Tx: +1 (median; IQR -1, 6) in IIEF; } \\
\text {-Sham: } 0 \text { (median; IQR -8, 4) in IIEF }\end{array}$ & $\begin{array}{l}\text { 1-month: } \\
\text { 0.07; }\end{array}$ \\
\hline & & & & & & & & & & & $\begin{array}{l}\text { 3-month: - -TX: +3.5 (median; IQR 0, 10) in IEEF; } \\
\text { Sham: - } 0.5 \text { (median; IQR -11, 1) in IIEF }\end{array}$ & $\begin{array}{c}\text { 3-month: } \\
0.0004\end{array}$ \\
\hline & & & & & & & & & & & 6-month: - Tx: 53\% w/EHS >2; Sham: $28 \%$ w/EHS >2 & \\
\hline $\begin{array}{l}\text { Kim et al. } \\
\text { (2020) }\end{array}$ & $\begin{array}{l}\text { Randomized, double-blind, } \\
\text { sham-controlled study }\end{array}$ & $38[43]$ & $\begin{array}{l}\text { Mild or moderate } \\
\text { vascular ED }\end{array}$ & $\begin{array}{l}\text { MT 2000H } \\
\text { (electromagnetic) }\end{array}$ & 3,000 & NA & $20 \mathrm{~mJ} / \mathrm{mm}^{2}$ (base) & NA & 12 & 7 wks post & - Tx: mean +5.1 in IIEF (mean EHS: $3.1+/-0.6$ ) & $<0.001$ \\
\hline & & & & & & & $12 \mathrm{~mJ} / \mathrm{mm}^{2}$ (distal penis) & & & & -Sham: mean 2.2 pts in IIEF (mean EHS: $2.4+/-0.9$ ) & \\
\hline
\end{tabular}


the effect of LiSWT for vasculogenic ED, but there have been at least two randomized, sham-controlled trials that evaluated treatment outcomes in men suffering from postpelvic surgery ED. Zewin et al. carried out a study involving 128 men with a history of nerve-sparing cystoprostatectomy due to muscle invasive bladder cancer (44). Patients were randomized to one of three arms: LiSWT-only, PDE5i-only, and no-treatment (control). 76\%, 79\%, and $61 \%$ of patients recovered "potency" at 9 -months after cystoprostatectomy, respectively. There was a statistically significant difference in IIEF-EF scores amongst all three treatment groups relative to baseline (postoperative), although there was no significant difference in the degree of recovery between the groups. Another study by Baccaglini et al. randomized patients to daily PDE5i (tadalafil 5-mg) starting after catheter removal versus PDE5i plus shockwave starting 6-weeks after radical prostatectomy (45). The primary clinical end-point for this trial was a fourpoint or greater increase in the mean IIEF-5 score favoring the treatment arm. The median baseline IIEF-5 scores for the treatment and control arm were similar (21 and 22 points, respectively; $\mathrm{P}=0.510)$. The study endpoint was defined at 3-weeks after the last LiSWT application or 16 weeks after prostatectomy. As expected, there was a drop in IIEF-5 scores compared with preoperative, but the median IIEF-5 was significant greater for the LiSWT arm (12; IQR 9.3, 15.8) compared with the control arm (10; IQR 7, $11 ; \mathrm{P}=0.006)$. However, this did not meet the pre-specified study endpoint criteria and the clinical implications of a two-point difference are questionable.

\section{Meta-analyses}

Given the variability seen in published outcomes, several groups have attempted to collate the data through metaanalyses to further delineate any beneficial effects with LiSWT on vasculogenic ED (46-53). As is seen in Table 3, despite significant differences in study inclusion criteria and technology considerations, all of the meta-analyses to date have shown a significant increase in IIEF scores (i.e., erectile function) for patients treated with LiSWT, both from baseline and relative to sham therapy. The mean difference (MD) in the IIEF between the treatment and sham arms ranged from approximately $+2-4$ points. Moreover, Sokolakis and Hatzichristodoulou found that patients treated with shockwave therapy were 8.5 times more likely to achieve a MCID in their IIEF score $(43,48)$.

\section{Who is likely to benefit from LiSWT?}

Several analyses also sought to identify patient and treatment factors associated with improved outcomes. In their systematic review and meta-analysis involving 14 studies (883 patients), Lu et al. showed that the IIEF of patients with mild ED increased significantly after LiSWT relative to sham [mean difference (MD) 2.86; $95 \% \mathrm{CI}$ : 1.54-4.19; $\mathrm{P}<0.0001]$, whereas patients with moderate and severe ED did not show a significant increase (49). IIEF increased more notably when LiSWT was combined with PDE5i use (MD 4.20; 95\% CI: 0.16-8.24; $\mathrm{P}=0.04$ ), supporting combination therapy. In contrast, a recent meta-analysis from Dong et al. found that patients with moderate and/or severe ED experienced greater improvements in their mean IIEF scores relative to patients with mild ED (MD: 3.95; 95\% CI: 2.44-5.46; $\mathrm{P}<0.00001)(53)$. Regarding technical specifications, the number of shocks per session varied between 1,500 to 5,000 , but the biggest improvement was seen with $>3,000$ (49). EFD varied from 0.09 to $0.25 \mathrm{~mJ} / \mathrm{mm}^{2}$. In their analysis of 9 studies ( $\mathrm{n}=637$ patients), Man and Li found that lower EFD (0.09 vs. 0.1-0.2 mJ/mm²; MD 4.14; 95\% CI: 0.87-7.42; $\mathrm{P}=0.01)$, increased number of shocks $(>3,000$ per session; MD 5.11; 95\% CI: 3.18-7.05; $\mathrm{P}=0.0001)$ and a shorter total treatment course ( $<6$ weeks; MD 3.73; 95\% CI: 0.54-6.93; $\mathrm{P}=0.02$ ) were all associated with improved outcomes.(51) It is important to emphasize that none of the included studies was specifically powered to evaluate these factors.

\section{Discussion}

The treatment paradigm for managing vasculogenic ED has remained relatively stagnant for the last two decades. In men who are unresponsive or intolerant of oral medications, we rely on vacuum erection devices, intracavernosal injections, intraurethral suppositories, and the gold-standard penile prosthesis. The latest iteration of the American Urological Association (AUA) guidelines shifted the discussion, positing that a rigid "stepwise" approach, wherein a patient was required to try and fail one option before moving on to the next, was preventing many patients from receiving the treatment needed to optimize their sexual function (3). Regenerative therapies have the potential to revolutionize our age-old approaches, given the perpetual push to develop novel, effective, and less invasive treatments for our patients. The underlying mechanisms for these treatments are sound-animal models supporting tissue regeneration by 
Table 3 Meta-analyses reviewing outcomes with low-intensity shockwave lithotripsy to treat erectile dysfunction

\begin{tabular}{|c|c|c|c|c|c|}
\hline Study Info & $\begin{array}{l}\text { Number } \\
\text { of studies } \\
\text { included }\end{array}$ & $\begin{array}{l}\text { Number of } \\
\text { patients }\end{array}$ & $\begin{array}{l}\text { Study inclusion } \\
\text { criteria }\end{array}$ & Findings & Other \\
\hline \multirow{2}{*}{ Man and Li (2017) } & & & & & $\begin{array}{l}\text { Lower energy density } \\
\left(0.09 \mathrm{~mJ} / \mathrm{mm}^{2}\right) \text {, increased } \\
\# \text { of pulses }(>3,000) \text {, and } \\
\text { shorter treatment course } \\
\text { (<6 weeks) resulted in } \\
\text { greater improvements }\end{array}$ \\
\hline & & & & & $\begin{array}{l}\text { Only } 1 / 3^{\text {rd }} \text { of studies have } \\
\text { good blinding and } 44 \% \text { of } \\
\text { studies had unclear risk of } \\
\text { bias in randomization }\end{array}$ \\
\hline \multirow[t]{2}{*}{ Zou et al. (2017) } & 4 RCTs & 277 & Vascular ED & $\begin{array}{l}\text { "Effective treatment" RR for LiSWT vs. placebo } \\
\text { was } 2.50(95 \% \mathrm{Cl}: 0.74,8.45) \text { based on IIEF-EF }\end{array}$ & \multirow{2}{*}{$\begin{array}{l}\text { 9-week protocol resulted } \\
\text { in better results versus } \\
5 \text {-week protocol }\end{array}$} \\
\hline & & & & $\begin{array}{l}\text { "Effective treatment" RR for LiSWT vs. placebo } \\
\text { was } 8.31(95 \% \mathrm{Cl}: 3.88,17.78) \text { based on EHS }\end{array}$ & \\
\hline Lu et al. (2016) & & & & & $\begin{array}{l}\text { Lower EFD } \\
\left(0.09 \mathrm{~mJ} / \mathrm{mm}^{2}\right) \text {, greater } \\
\text { number of shocks, and } \\
\text { shorter treatment } \\
\text { duration resulted in } \\
\text { greater improvements } \\
\text { in IIEF }\end{array}$ \\
\hline Clavijo et al. (2017) & 7 RCTs & 602 & Vascular ED & $\begin{array}{l}\text { LiSWT resulted in a } 4.17 \text {-point }(95 \% \mathrm{Cl}:-0.5 \text {, } \\
8.3 ; \mathrm{P}<0.0001) \text { difference relative to } \\
\text { sham-control }\end{array}$ & $\begin{array}{l}\text { No difference seen in } \\
\text { sub-analysis controlling } \\
\text { for follow-up, participant } \\
\text { age, and baseline } \\
\text { IIEF-EF scores }\end{array}$ \\
\hline
\end{tabular}

Table 3 (continued) 
Table 3 (continued)

\begin{tabular}{|c|c|c|c|c|c|}
\hline Study Info & $\begin{array}{l}\text { Number } \\
\text { of studies } \\
\text { included }\end{array}$ & $\begin{array}{l}\text { Number of } \\
\text { patients }\end{array}$ & $\begin{array}{c}\text { Study inclusion } \\
\text { criteria }\end{array}$ & Findings & Other \\
\hline $\begin{array}{l}\text { Campbell et al. } \\
\text { (2019) }\end{array}$ & 7 RCTs & 607 & Vascular ED & $\begin{array}{l}\text { Patients who underwent LiSWT were more likely } \\
\text { to experience an improvement in EHS (RR 6.63; } \\
95 \% \mathrm{Cl}: 1.59,27.71 ; \mathrm{P}=0.0095)\end{array}$ & $\mathrm{N} / \mathrm{A}$ \\
\hline $\begin{array}{l}\text { Sokolakis and } \\
\text { Hatzichristodoulou } \\
\text { (2019) }\end{array}$ & $10 \mathrm{RCTs}$ & 873 & Vascular ED & $\begin{array}{l}\% \text { of patients achieving a MCID in IIEF-EF in the } \\
\text { LiSWT group was significantly greater relative to } \\
\text { sham (OR } 8.54 ; 95 \% \mathrm{Cl}: 2.64,27.63 ; P=0.0003 \text { ) }\end{array}$ & $\begin{array}{l}\text { Subgroup analysis of } \\
\text { PDE5I responders } \\
\text { revealed a significantly } \\
\text { greater increase in IIEF-EF } \\
\text { from baseline and a } \\
\text { greater proportion of } \\
\text { patients achieving MCID }\end{array}$ \\
\hline Dong et al. (2019) & $7 \mathrm{RCTs}$ & 522 & Vascular ED & $\begin{array}{l}\text { IIEF scores at } 1 \text {-month after tx were } \\
\text { significantly improved relative to baseline in the } \\
\text { LiSWT treated patients compared with sham } \\
\text { (MD } 1.99 \text { points; } 95 \% \mathrm{Cl}: 1.35,2.63 \text {; } \mathrm{P}<0.0001 \text { ) }\end{array}$ & $\mathrm{N} / \mathrm{A}$ \\
\hline
\end{tabular}

neovascularization and neurogenesis. However, translating these findings into human data with evidence of clinically meaningful positive outcomes is mandatory prior to upending the status quo.

Data continues to amass with respect to LiSWT as a treatment for vasculogenic ED. At least 11 randomized, sham-controlled trials have sought to evaluate treatment outcomes, with $>60 \%$ showing a statistically significant increase in IIEF scores favoring LiSWT (mean improvement ranging from 1-12.5 points). Studies in other populations such as those with pelvic surgery have shown a benefit as well $(35,44)$. To this end, of the at least eight available meta-analyses, all have supported a statistically significant increase in IIEF-scores with LiSWT (46-53). Due to significant heterogeneity in the study protocols, what remains unknown is what patient characteristics will optimize outcomes with LiSWT. There are some signals from the meta-analyses. For example, Lu et al. found that patients with mild ED had a significant improvement over sham, whereas those with moderate and severe ED did not (49). Also, Sokolakis and Hatzichristodoulou reported that PDE5i responders were more likely to achieve MCID criteria (48). Others such as Clavijo et al. reported conflicting results with respect to baseline IIEFscore and likelihood of response, and there are nonrandomized studies showing that PDE5i non-responders may be "salvaged" with LiSWT (50). A recent multi-center, prospective, single-arm series from Palmieri et al. found that LiSWT, when combined with PDE5i therapy, resulted in an average increase in IIEF-EF score of 8.6 points in PDE5i "non-responders" (54). 71\% achieved a MCID in their IIEF-EF scores, and $68 \%$ had an EHS $\geq 3$ (i.e., rigidity sufficient for penetration). Interestingly, ED symptom duration does not appear to influence results based on a result study from De Oliveira et al. (55).

We must also consider treatment protocols which include potential variations in energy settings, number of applied shocks, and treatment duration. Patel et al. found no difference in treatment success in their phase II trial comparing a similar number of shocks $(3,600)$ delivered over one versus two weeks (56). Kalyvianakis et al. similarly did not identify a significant difference in outcomes based 
on the number of sessions administered per week (two versus three) and varying energy-flux density (0.05 vs. $0.1 \mathrm{~mJ} / \mathrm{mm}^{2}$ ) (46). In contrast to this, a meta-analysis found that applying a greater number of shocks (at least 3,000 ) and using a lower EFD (0.09 vs. $0.1-0.2 \mathrm{~mJ} / \mathrm{mm}^{2}$ ) may optimize outcomes (49). Future work must focus on delineating the technical settings that will enhance outcomes for our patients if this therapy is to be considered a mainstay.

A final important caveat when offering a treatment is the longevity of positive results. Put another way-do the beneficial effects persist after the treatment has ceased? As seen in Table 2, the majority of available studies assessed short term outcomes at 1-3 months post-treatment. In their 2018 study, Kitrey et al. sought to further evaluate the persistence of symptom improvement after LiSWT (57). The authors followed 156 patients included in several different previous study protocols. $99 / 156$ patients $(64 \%)$ were classified as treatment successes at one-month (based on achieving a MCID in IIEF-EF). However, by two years post-treatment, only $53 \%(53 / 99)$ of these original treatment "successes" were able to maintain the beneficial effects of LiSWT without maintenance therapy. $0 \%$ of patient with baseline diabetes mellitus or "severe" ED maintained the beneficial effects at two years, as compared to $76 \%$ in those with "mild" baseline ED and no diabetes. This underscores the importance of patient selection and pre-treatment counseling to ensure the highest likelihood of success.

There are several national and international organizations that have published guideline recommendations surrounding LiSWT including the AUA (2018), Asia-Pacific Society for Sexual Medicine (APSSM; 2020), European Society of Sexual medicine (ESSM; 2019), and European Association of Urology (EAU; 2020) (3,58-60). All organizations acknowledge LiSWT as a potential treatment for ED with promising early clinical studies. The treatment appears safe with minimal risk for serious adverse events. The majority of adverse events seen in the randomized trials were mild and transient, and there have been no dropouts reported as a result of treatment adverse effects (58). This is true even amongst patients considered higher risk such as those on anti-coagulation or anti-platelet therapy for cardiovascular disease (61). However, due to heterogeneity in the literature surrounding treatment protocols and study populations, further investigation is necessary before we can label LiSWT as "standard of care" outside the scope of clinical research. Accordingly, LiSWT is recommended by the EAU as a first-line treatment alternative in patients with vasculogenic ED who are uninterested or unable to tolerate oral therapy and who are poor PDE5i responders, but this is based on weak evidence (60). The APSSM similarly suggests that LiSWT be offered to men with mild/moderate vasculogenic ED who do or do not respond to PDE5i (level 2; grade b) (58). The AUA and ESSM, in contrast, consider LiSWT as deserving of more investigation or experimental, respectively $(3,59)$.

\section{Conclusions}

Vasculogenic ED is common, and regenerative therapies have the potential to transform our historical treatment paradigms. LiSWT is one such approach that, based on promising animal model data, encourages tissue regeneration through various mechanism including angiogenesis, neurogenesis, and progenitor cell recruitment. Several early single-arm studies and multiple randomized, sham-controlled trials support a possible therapeutic benefit for men with vasculogenic ED. Based on the currently available data, LiSWT appears most likely to benefit patients with mild/moderate ED and few medical comorbidities. LiSWT may optimize response to PDE5i or enhance medication response in PDE5i "non-responders". Linear ultrasound probes (as opposed to radial) should be considered standard of care. They are the only probes that have been consistently shown to benefit patients based on the available literature, although in practice radial shockwave probes are commonplace. Future work is needed to investigate device technologies, therapeutic administrative protocols (number of shocks, treatment duration), and patient characteristics associated with optimal treatment outcomes. In the meantime, appropriate pre-treatment expectations must be discussed at the outset. Patients should be adequately counseled regarding what is known and unknown about LiSWT, particularly as it pertains to treatment protocols and study populations within the context of clinical studies.

\section{Acknowledgments}

Funding: None.

\section{Footnote}

Provenance and Peer Review: This article was commissioned by the Guest Editors (Francisco E. Martins and Tobias S. 
Köhler) for the series "Controversies and Considerations of Penile Surgery" published in Translational Andrology and Urology. The article has undergone external peer review.

Reporting Checklist: The authors have completed the Narrative Review Checklist. Available at http://dx.doi. org/10.21037/tau-20-1286

Conflicts of Interest: The authors have completed the ICMJE uniform disclosure form (available at http://dx.doi. org/10.21037/tau-20-1286). The series "Controversies and Considerations of Penile Surgery" was commissioned by the editorial office without any funding or sponsorship. The authors have no other conflicts of interest to declare.

Ethical Statement: The authors are accountable for all aspects of the work in ensuring that questions related to the accuracy or integrity of any part of the work are appropriately investigated and resolved.

Open Access Statement: This is an Open Access article distributed in accordance with the Creative Commons Attribution-NonCommercial-NoDerivs 4.0 International License (CC BY-NC-ND 4.0), which permits the noncommercial replication and distribution of the article with the strict proviso that no changes or edits are made and the original work is properly cited (including links to both the formal publication through the relevant DOI and the license). See: https://creativecommons.org/licenses/by-nc-nd/4.0/.

\section{References}

1. Feldman HA, Goldstein I, Hatzichristou DG, et al. Impotence and its medical and psychosocial correlates: results of the Massachusetts Male Aging Study. J Urol 1994;151:54-61.

2. Corona G, Lee DM, Forti G, et al. Age-related changes in general and sexual health in middle-aged and older men: results from the European Male Ageing Study (EMAS). J Sex Med 2010;7:1362-80.

3. Burnett AL, Nehra A, Breau RH, et al. Erectile Dysfunction: AUA Guideline. J Urol 2018;200:633-41.

4. Iacono F, Giannella R, Somma P, et al. Histological alterations in cavernous tissue after radical prostatectomy. J Urol 2005;173:1673-6.

5. Liu MC, Chang ML, Wang YC, et al. Revisiting the Regenerative Therapeutic Advances Towards Erectile Dysfunction. Cells 2020;9:1250.
6. Jenkins LC, Mulhall JP. The New Business of ED Therapy. J Sex Med 2015;12:2223-5.

7. McClain PD, Lange JN, Assimos DG. Optimizing shock wave lithotripsy: a comprehensive review. Rev Urol 2013;15:49-60.

8. Kuo YR, Wang CT, Wang FS, et al. Extracorporeal shock wave treatment modulates skin fibroblast recruitment and leukocyte infiltration for enhancing extended skin-flap survival. Wound Repair Regen 2009;17:80-7.

9. Brunckhorst $\mathrm{O}$, Wells $\mathrm{L}$, Teeling F, et al. A systematic review of the long-term efficacy of low-intensity shockwave therapy for vasculogenic erectile dysfunction. Int Urol Nephrol 2019;51:773-81.

10. Salter CA, Lue TF, Mulhall JP. What Is Shockwave Therapy? J Sex Med 2020;17:565-9.

11. Capogrosso P, Di Mauro M, Fode M, et al. Low-intensity extracorporeal shockwave therapy among urologist practitioners: how the opinion of urologists changed between 2016 and 2019. Int J Impot Res 2020. [Epub ahead of print]. doi: 10.1038/s41443-020-00347-x.

12. Chung E, Wang J. A state-of-art review of low intensity extracorporeal shock wave therapy and lithotripter machines for the treatment of erectile dysfunction. Expert Rev Med Devices 2017;14:929-34.

13. Apfel RE. Acoustic cavitation: a possible consequence of biomedical uses of ultrasound. Br J Cancer Suppl 1982;5:140-6.

14. Yahata K, Kanno H, Ozawa H, et al. Low-energy extracorporeal shock wave therapy for promotion of vascular endothelial growth factor expression and angiogenesis and improvement of locomotor and sensory functions after spinal cord injury. J Neurosurg Spine 2016;25:745-55.

15. Sağir D, Bereket C, Onger ME, et al. Efficacy of Extracorporeal Shockwaves Therapy on Peripheral Nerve Regeneration. J Craniofac Surg 2019;30:2635-9.

16. Pahakis MY, Kosky JR, Dull RO, et al. The role of endothelial glycocalyx components in mechanotransduction of fluid shear stress. Biochem Biophys Res Commun 2007;355:228-33.

17. Traub O, Berk BC. Laminar shear stress: mechanisms by which endothelial cells transduce an atheroprotective force. Arterioscler Thromb Vasc Biol 1998;18:677-85.

18. Davies PF. Flow-mediated endothelial mechanotransduction. Physiol Rev 1995;75:519-60.

19. Ha CH, Kim S, Chung J, et al. Extracorporeal shock wave stimulates expression of the angiogenic genes via mechanosensory complex in endothelial cells: mimetic 
effect of fluid shear stress in endothelial cells. Int J Cardiol 2013;168:4168-77.

20. Hatanaka K, Ito K, Shindo T, et al. Molecular mechanisms of the angiogenic effects of low-energy shock wave therapy: roles of mechanotransduction. Am J Physiol Cell Physiol 2016;311:C378-85.

21. Sokolakis I, Dimitriadis F, Psalla D, et al. Effects of lowintensity shock wave therapy (LiST) on the erectile tissue of naturally aged rats. Int J Impot Res 2019;31:162-9.

22. Liu J, Zhou F, Li GY, et al. Evaluation of the effect of different doses of low energy shock wave therapy on the erectile function of streptozotocin (STZ)-induced diabetic rats. Int J Mol Sci 2013;14:10661-73.

23. Assaly R, Giuliano F, Clement P, et al. Extracorporeal Shock Waves Therapy Delivered by Aries Improves Erectile Dysfunction in Spontaneously Hypertensive Rats Through Penile Tissue Remodeling and Neovascularization. Sex Med 2019;7:441-50.

24. Murata R, Ohtori S, Ochiai N, et al. Extracorporeal shockwaves induce the expression of ATF3 and GAP43 in rat dorsal root ganglion neurons. Auton Neurosci 2006;128:96-100.

25. Li H, Matheu MP, Sun F, et al. Low-energy Shock Wave Therapy Ameliorates Erectile Dysfunction in a Pelvic Neurovascular Injuries Rat Model. J Sex Med 2016;13:22-32.

26. Lin G, Reed-Maldonado AB, Wang B, et al. In Situ Activation of Penile Progenitor Cells With LowIntensity Extracorporeal Shockwave Therapy. J Sex Med 2017;14:493-501.

27. Rassweiler JJ, Knoll T, Köhrmann KU, et al. Shock wave technology and application: an update. Eur Urol 2011;59:784-96.

28. Manzoor H, Saikali SW. Renal Extracorporeal Lithotripsy. StatPearls. Treasure Island (FL): StatPearls Publishing Copyright (C) 2020, StatPearls Publishing LLC.; 2020.

29. Katz JE, Clavijo RI, Rizk P, et al. The Basic Physics of Waves, Soundwaves, and Shockwaves for Erectile Dysfunction. Sex Med Rev 2020;8:100-5.

30. Wang YC, Chen SJ, Huang PJ, et al. Efficacy of Different Energy Levels Used in Focused and Radial Extracorporeal Shockwave Therapy in the Treatment of Plantar Fasciitis: A Meta-Analysis of Randomized Placebo-Controlled Trials. J Clin Med 2019;8:1497.

31. Vardi Y, Appel B, Jacob G, et al. Can low-intensity extracorporeal shockwave therapy improve erectile function? A 6-month follow-up pilot study in patients with organic erectile dysfunction. Eur Urol 2010;58:243-8.
32. Vardi Y, Appel B, Kilchevsky A, et al. Does low intensity extracorporeal shock wave therapy have a physiological effect on erectile function? Short-term results of a randomized, double-blind, sham controlled study. J Urol 2012;187:1769-75.

33. Fojecki GL, Tiessen S, Osther PJ. Effect of Low-Energy Linear Shockwave Therapy on Erectile Dysfunction-A Double-Blinded, Sham-Controlled, Randomized Clinical Trial. J Sex Med 2017;14:106-12.

34. Olsen AB, Persiani M, Boie S, et al. Can low-intensity extracorporeal shockwave therapy improve erectile dysfunction? A prospective, randomized, double-blind, placebo-controlled study. Scand J Urol 2015;49:329-33.

35. Vinay J, Moreno D, Rajmil O, et al. Penile low intensity shock wave treatment for PDE5I refractory erectile dysfunction: a randomized double-blind sham-controlled clinical trial. World J Urol 2020. [Epub ahead of print]. doi: 10.1007/s00345-020-03373-y.

36. Srini VS, Reddy RK, Shultz T, et al. Low intensity extracorporeal shockwave therapy for erectile dysfunction: a study in an Indian population. Can J Urol 2015;22:7614-22.

37. Yee CH, Chan ES, Hou SS, et al. Extracorporeal shockwave therapy in the treatment of erectile dysfunction: a prospective, randomized, double-blinded, placebo controlled study. Int J Urol 2014;21:1041-5.

38. Motil I, Kubis I, Sramkova T. Treatment of vasculogenic erectile dysfunction with Piezowave2 device. Application of low intensity shockwaves using novel linear shockwave tissue coverage (LSTC-ED®) technique. A prospective, multicentric, placebo-controlled study. Advances in Sexual Medicine 2016;6:15.

39. Kitrey ND, Gruenwald I, Appel B, et al. Penile Low Intensity Shock Wave Treatment is Able to Shift PDE5i Nonresponders to Responders: A Double-Blind, Sham Controlled Study. J Urol 2016;195:1550-5.

40. Yamaçake KG, Carneiro F, Cury J, et al. Low-intensity shockwave therapy for erectile dysfunction in kidney transplant recipients. A prospective, randomized, double blinded, sham-controlled study with evaluation by penile Doppler ultrasonography. International journal of impotence research 2019;31:195-203.

41. Kalyvianakis D, Hatzichristou D. Low-Intensity Shockwave Therapy Improves Hemodynamic Parameters in Patients With Vasculogenic Erectile Dysfunction: A Triplex Ultrasonography-Based Sham-Controlled Trial. J Sex Med 2017;14:891-7.

42. Kim KS, Jeong HC, Choi SW, et al. Electromagnetic Low-Intensity Extracorporeal Shock Wave Therapy in 
Patients with Erectile Dysfunction: A Sham-Controlled, Double-Blind, Randomized Prospective Study. World J Mens Health 2020;38:236-42.

43. Rosen RC, Allen KR, Ni X, et al. Minimal clinically important differences in the erectile function domain of the International Index of Erectile Function scale. Eur Urol 2011;60:1010-6.

44. Zewin TS, El-Assmy A, Harraz AM, et al. Efficacy and safety of low-intensity shock wave therapy in penile rehabilitation post nerve-sparing radical cystoprostatectomy: a randomized controlled trial. Int Urol Nephrol 2018;50:2007-14.

45. Baccaglini W, Pazeto CL, Corrêa Barros EA, et al. The Role of the Low-Intensity Extracorporeal Shockwave Therapy on Penile Rehabilitation After Radical Prostatectomy: A Randomized Clinical Trial. J Sex Med 2020;17:688-94.

46. Angulo JC, Arance I, de Las Heras MM, et al. Efficacy of low-intensity shock wave therapy for erectile dysfunction: A systematic review and meta-analysis. Actas Urol Esp 2017;41:479-90.

47. Campbell JD, Trock BJ, Oppenheim AR, et al. Metaanalysis of randomized controlled trials that assess the efficacy of low-intensity shockwave therapy for the treatment of erectile dysfunction. Ther Adv Urol 2019;11:1756287219838364.

48. Sokolakis I, Hatzichristodoulou G. Clinical studies on low intensity extracorporeal shockwave therapy for erectile dysfunction: a systematic review and metaanalysis of randomised controlled trials. Int J Impot Res 2019;31:177-94.

49. Lu Z, Lin G, Reed-Maldonado A, et al. Low-intensity Extracorporeal Shock Wave Treatment Improves Erectile Function: A Systematic Review and Meta-analysis. Eur Urol 2017;71:223-33.

50. Clavijo RI, Kohn TP, Kohn JR, et al. Effects of LowIntensity Extracorporeal Shockwave Therapy on Erectile Dysfunction: A Systematic Review and Meta-Analysis. J Sex Med 2017;14:27-35.

51. Man L, Li G. Low-intensity Extracorporeal Shock Wave Therapy for Erectile Dysfunction: A Systematic Review and Meta-analysis. Urology 2018;119:97-103.

52. Zou ZJ, Tang LY, Liu ZH, et al. Short-term efficacy and safety of low-intensity extracorporeal shock wave therapy in erectile dysfunction: a systematic review and metaanalysis. Int Braz J Urol 2017;43:805-21.

53. Dong L, Chang D, Zhang X, et al. Effect of Low-Intensity Extracorporeal Shock Wave on the Treatment of Erectile
Dysfunction: A Systematic Review and Meta-Analysis. Am J Mens Health 2019;13:1557988319846749.

54. Palmieri A, Arcaniolo D, Palumbo F, et al. Low intensity shockwave therapy in combination with phosphodiesterase-5 inhibitors is an effective and safe treatment option in patients with vasculogenic ED who are PDE5i non-responders: a multicenter single-arm clinical trial. Int J Impot Res 2020. [Epub ahead of print]. doi: 10.1038/s41443-020-0332-7.

55. De Oliveira PS, De Oliveira TR, Nunes Á, et al. Lowintensity shock wave therapy for erectile dysfunction and the influence of disease duration. Arch Ital Urol Androl 2019;90:276-82.

56. Patel P, Katz J, Lokeshwar SD, et al. Phase II Randomized, Clinical Trial Evaluating 2 Schedules of Low-Intensity Shockwave Therapy for the Treatment of Erectile Dysfunction. Sex Med 2020;8:214-22.

57. Kitrey ND, Vardi Y, Appel B, et al. Low Intensity Shock Wave Treatment for Erectile Dysfunction-How Long Does the Effect Last? J Urol 2018;200:167-70.

58. Chung E, Lee J, Liu CC, et al. Clinical Practice Guideline Recommendation on the Use of Low Intensity Extracorporeal Shock Wave Therapy and Low Intensity Pulsed Ultrasound Shock Wave Therapy to Treat Erectile Dysfunction: The Asia-Pacific Society for Sexual Medicine Position Statement. World J Mens Health 2021;39:1-8.

59. Capogrosso P, Frey A, Jensen CFS, et al. Low-Intensity Shock Wave Therapy in Sexual Medicine-Clinical Recommendations from the European Society of Sexual Medicine (ESSM). J Sex Med 2019;16:1490-505.

60. Salonia A, Bettocchi C, Carvalho J, et al. (EAU Sexual and Reproductive Health Guidelines Panel). European Association of Urology Sexual and Reporductive Health Guidelines. EAU Guidelines Edn presented at the EAU Annual Congress Amsterdam 2020 ISBN 978-94-9267107-3 2020.

61. Kalyvianakis D, Memmos D, Mykoniatis I, et al. LowIntensity Shockwave Therapy (LiST) for Erectile Dysfunction: Is It Safe for Patients on Anticoagulant Medication? J Sex Med 2019;16:1478-80.

Cite this article as: de Oliveira PS, Ziegelmann MJ. Lowintensity shock wave therapy for the treatment of vasculogenic erectile dysfunction: a narrative review of technical considerations and treatment outcomes. Transl Androl Urol 2021;10(6):2617-2628. doi: 10.21037/tau-20-1286 